\title{
BMJ Open Translating the Symptom Screening in Pediatrics Tool (SSPedi) into Argentinian Spanish for paediatric patients receiving cancer treatments, and evaluating understandability and cultural relevance in a multiple-phase descriptive study
}

\author{
Sergio Gomez, ${ }^{1}$ Carmen Salaverria, ${ }^{2}$ Erin Plenert, ${ }^{3}$ Gisela Gonzalez, ${ }^{1}$ \\ Gisela D'Angelo, ${ }^{1}$ Allison Grimes, ${ }^{4}$ Aaron Sugalski, ${ }^{4}$ Anne-Marie Langevin, ${ }^{4}$ \\ Lee Dupuis, ${ }^{3,5}$ Lillian Sung (i) ${ }^{3,6}$
}

To cite: Gomez S, Salaverria C, Plenert E, et al. Translating the Symptom Screening in Pediatrics Tool (SSPedi) into Argentinian Spanish for paediatric patients receiving cancer treatments, and evaluating understandability and cultural relevance in a multiple-phase descriptive study. BMJ Open 2021;11:e048287. doi:10.1136/ bmjopen-2020-048287

- Prepublication history and additional material for this paper is available online. To view these files, please visit the journal online (http://dx.doi.org/10. 1136/bmjopen-2020-048287).

Received 22 December 2020 Revised 04 March 2021 Accepted 19 March 2021
Check for updates

(C) Author(s) (or their employer(s)) 2021. Re-use permitted under CC BY-NC. No commercial re-use. See rights and permissions. Published by BMJ.

For numbered affiliations see end of article.

Correspondence to

Dr Lillian Sung;

lillian.sung@sickkids.ca

\section{ABSTRACT}

Objectives To translate a symptom screening tool developed for paediatric patients receiving cancer therapies called Symptom Screening in Pediatrics Tool (SSPedi) into Argentinian Spanish and to evaluate the understandability and cultural relevance of the translated version of SSPedi among children with cancer and paediatric haematopoietic stem cell transplant (HSCT) recipients.

Methods We conducted a multiphase, descriptive study to translate SSPedi into Argentinian Spanish. Using two translators, forward and backward translations were performed. The translated version was evaluated by Spanish-speaking paediatric patients 8-18 years of age receiving cancer treatments in two centres in Argentina and El Salvador.

Primary and secondary outcome measures The primary outcome was patient self-reported difficulty with understanding of the SSPedi instructions and each symptom using a 5-point Likert scale. Secondary outcomes were incorrect understanding of the SSPedi instructions, symptoms and response scale determined by cognitive interviews with the patients and rated using a 4-point Likert scale. Cultural relevance was assessed qualitatively.

Results There were 30 children enrolled and included in cognitive interviews; 16 lived in Argentina and 14 lived in El Salvador. The most common types of Spanish spoken were Central American $(17,57 \%)$ followed by South American (10, 33\%) and Castilian (3, 10\%). No changes to Argentinian Spanish SSPedi were required based on the outcomes or qualitative comments. No issues with cultural relevance were identified by any of the respondents.

Conclusions We translated and finalised Argentinian Spanish SSPedi. Future research will focus on its use to describe bothersome symptoms by Argentinian Spanishspeaking children.
Strengths and limitations of this study

Multiple approaches to assessing understandability is a strength as it improves robustness and validity of the findings.

- Use of an independent adjudicator is a strength as it improves reliability of the results.

- Finalisation of a symptom screening tool intended for use in low-income and middle-income countries is a strength.

The study is limited by its small sample size.

\section{BACKGROUND}

Symptoms are an important problem for paediatric patients receiving cancer therapies. ${ }^{1-3}$ We previously proposed that active symptom screening and feedback to healthcare providers are important to improving symptom control. ${ }^{4}{ }^{5}$ Active symptom screening can identify symptoms earlier, facilitate communication with healthcare providers and improve implementation of symptom management strategies.

To allow patients to report and track their symptoms, we developed and established favourable psychometric properties of an instrument called the Symptom Screening in Pediatrics Tool (SSPedi), which was created for paediatric patients receiving cancer treatments. ${ }^{6} 7$ SSPedi records the degree of bother paediatric patients experienced yesterday or today related to 15 symptoms on a 5-point Likert scale. The 15 symptoms are as follows: disappointed or sad, scared or worried, cranky or angry, problems thinking, body or face changes, tiredness, mouth sores, 


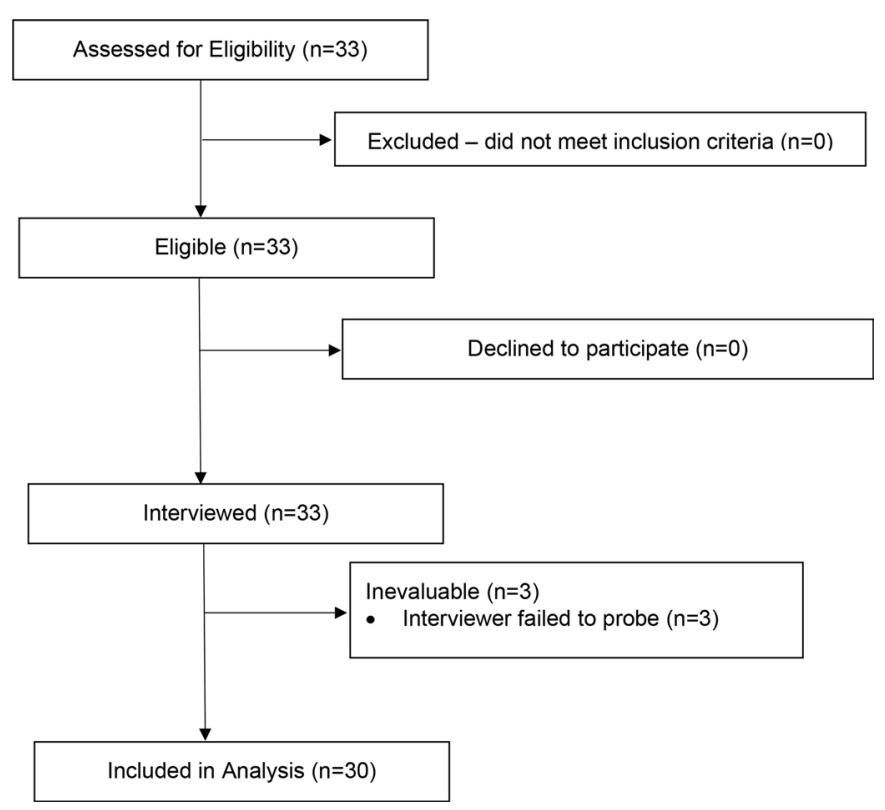

Figure 1 Participant identification and enrolment flow diagram.

headache, other pain, tingling or numbness, throwing up, hunger changes, taste changes, constipation and diarrhoea. SSPedi exhibited internal consistency, test-retest and inter-rater reliability, construct validity and responsiveness to change among English-speaking paediatric patients $8-18$ years of age. ${ }^{\text {? }}$

To allow SSPedi to be used in non-English-speaking settings, we began to translate it into other languages. We translated SSPedi into French and found that the translated version was understandable and culturally appropriate in Canada and France. ${ }^{8}$ We also focused on translation to Spanish. ${ }^{9}$ During this translation process, we identified that at least two versions of Spanish would be required, namely, one appropriate for North America and one appropriate for Argentina. This distinction arose from differences in common language, grammatical structure and use of voseo conjugation in Argentina. In voseo conjugation, 'vos' is used instead of, or alongside 'tu' as a second-person singular pronoun. The North American version of Spanish SSPedi was found to be understandable and culturally appropriate in the USA and Canada. Consequently, the next step was to develop and evaluate an Argentinian version of Spanish SSPedi. The current study's objectives were to translate SSPedi into Argentinian Spanish and to evaluate the understandability and cultural relevance of the translated version of SSPedi among children with cancer and paediatric haematopoietic stem cell transplant (HSCT) recipients.

\section{METHODS}

All study participants or guardians provided informed consent or assent as appropriate. The conduct of this study followed that suggested by the ISPOR Task Force, and online supplemental appendix 1 shows a flowchart of the translation process. ${ }^{10}$

\section{Translation}

As previously described, we convened a panel consisting of Spanish-speaking investigators and translators from the USA, Canada and Argentina. ${ }^{9}$ The documents translated were as follows: instructions for completing SSPedi, each symptom, the degree of bother response scale and a synonym list of symptoms for patients who had difficulty understanding a symptom.

Translation included the following four steps: forward translation, reconciliation, back translation and back translation review. Forward translation consisted of the independent translation of SSPedi from English (source language) by two professional medical translators who were both educated in the country targeted for translation. One of the translators resided in the target country at the time of translation. The two translated versions were reconciled by the translation panel.

The reconciled version in Argentinian Spanish was then back translated to English by a third translator. This translator was a native English speaker who did not have knowledge of English SSPedi. The translation panel reviewed the back translation to determine if any discrepancies in meaning were introduced in the translation process. This was performed during an online meeting where each back-translated item was reviewed and discussed among the panel members. Decisions were made by consensus.

\section{Cognitive interviews}

The purpose of the cognitive interviews was to determine if Argentinian Spanish SSPedi was difficult to understand, incorrectly understood and culturally inappropriate. Participants were enrolled from one hospital in La Plata, Argentina (Hospital Sor Maria Ludovica), and one hospital in San Salvador, El Salvador (Benjamin Bloom National Children's Hospital). The Salvadorian investigator (CS) decided that the form of Spanish spoken in El Salvador was sufficiently similar to Spanish spoken in Argentina to use this version. We included patients who were 8-18 years of age with a diagnosis of cancer or undergoing HSCT if Spanish was their first language. Patients with visual or cognitive impairments that precluded completion of SSPedi according to their healthcare provider were excluded.

In Argentina, physicians (SG, GG and GD) interviewed participants, while in El Salvador, a psychologist (CS) interviewed participants. Potential participants were identified by the healthcare team. Eligible patients were purposively sampled to ensure that children of varying ages, underlying diagnoses and sex were included. Identified patients were approached to request consent or assent to participate.

Consenting patients completed Argentinian Spanish SSPedi on paper; it could be completed on their own or read aloud to them. On completion of SSPedi, the patients first rated how easy or hard Argentinian Spanish SSPedi was to understand on a 5-point Likert scale ranging from $1=$ 'very hard' to $5=$ ='very easy'. Difficulty understanding was rated for the SSPedi instructions and 
Table 1 Demographics of participants stratified by cohort

\begin{tabular}{|c|c|c|c|}
\hline & $\begin{array}{l}\text { Cohort } 1 \\
(n=10)\end{array}$ & $\begin{array}{l}\text { Cohort } 2 \\
(n=10)\end{array}$ & $\begin{array}{l}\text { Cohort } 3 \\
(n=10)\end{array}$ \\
\hline \multicolumn{4}{|l|}{ Country of residence } \\
\hline Argentina & 7 & 3 & 6 \\
\hline El Salvador & 3 & 7 & 4 \\
\hline \multicolumn{4}{|l|}{ Age in years } \\
\hline $8-10$ & 2 & 1 & 2 \\
\hline $11-14$ & 6 & 5 & 6 \\
\hline $15-18$ & 2 & 4 & 2 \\
\hline Male sex & 6 & 6 & 7 \\
\hline \multicolumn{4}{|l|}{ Diagnosis } \\
\hline Leukaemia & 9 & 8 & 7 \\
\hline Lymphoma & 0 & 2 & 1 \\
\hline Solid tumour & 0 & 0 & 1 \\
\hline Brain tumour & 0 & 0 & 0 \\
\hline Other & 1 & 0 & 1 \\
\hline Metastatic disease & 5 & 2 & 3 \\
\hline On active treatment & 7 & 10 & 10 \\
\hline $\begin{array}{l}\text { Haematopoietic stem cell } \\
\text { transplantation }\end{array}$ & 7 & 1 & 2 \\
\hline Attending school & 5 & 8 & 7 \\
\hline \multicolumn{4}{|l|}{ Dialect of Spanish } \\
\hline Mexican & 0 & 0 & 0 \\
\hline Central American & 5 & 8 & 4 \\
\hline South American & 5 & 2 & 3 \\
\hline Spain (Castilian) & 0 & 0 & 3 \\
\hline Other & 0 & 0 & 0 \\
\hline \multicolumn{4}{|l|}{ Confident speaking Spanish } \\
\hline Not at all & 0 & 0 & 0 \\
\hline Not very & 0 & 0 & 0 \\
\hline Somewhat & 1 & 0 & 0 \\
\hline Confident & 3 & 0 & 2 \\
\hline Very confident & 6 & 10 & 8 \\
\hline \multicolumn{4}{|l|}{ Confident reading Spanish } \\
\hline Not at all & 0 & 0 & 0 \\
\hline Not very & 1 & 0 & 0 \\
\hline Somewhat & 0 & 0 & 0 \\
\hline Confident & 4 & 1 & 2 \\
\hline Very confident & 5 & 9 & 8 \\
\hline
\end{tabular}

for each of the 15 symptoms. The number of patients who found each SSPedi item hard or very hard to understand was tabulated. Second, the patient's understanding of the SSPedi instructions, each symptom and the response scale were evaluated using cognitive probing. The interviews were audio-recorded and sent to Toronto. The interviewer and an independent rater in Toronto adjudicated understanding using a 4-point Likert scale ranging from $1=$ ='completely incorrect' to $4=$ ='completely correct'. Discrepancies were resolved by consensus. The number of patients who were rated as partially or completely incorrect was tabulated. Third, to assess cultural relevance, we asked patients whether any of the SSPedi items did not make sense to them in thinking about their day-to-day life. These responses were dichotomised by the Torontobased rater as present or absent. Lastly, we asked whether any important symptoms were missing from Argentinian Spanish SSPedi. Interviews were considered evaluable if the child understood the questions being asked and the interviewer performed sufficient probing to allow adjudication of understanding.

The outcomes of the study were the number of patients who found each SSPedi item hard to understand, the number who incorrectly understood each SSPedi item and issues with cultural relevance. In high-income countries, the thresholds for modification were if among 10 participants, 2 found a symptom hard to understand or were incorrect in their understanding of a symptom. In other words, at most, 1 in the last group of 10 participants could have some difficulty with a symptom. However, even in a high-income country such as Canada, paediatric patients had more difficulty with some subjective symptoms and, more specifically, found changes in how your body and face look, tingly or numb hands or feet and constipation were more challenging to understand. ${ }^{11}$ We hypothesised that paediatric patients in low-income and middle-income countries may find symptoms more difficult to understand related to differences in education and thus, made a pragmatic decision to modify these thresholds in this setting a priori. These thresholds were that modification would be required if among 10 participants, 3 found a symptom hard to understand or were incorrect in their understanding of a symptom. In other words, at most two participants could have some difficulty with a symptom.

\section{Evaluation of responses}

Each child was interviewed separately. The study team met to review the responses of each consecutive group of five interviews to determine whether Argentinian Spanish SSPedi required modification. Evaluation of outcomes, or the number of patients who found each SSPedi item hard to understand, the number who incorrectly understood each SSPedi item and issues with cultural relevance were examined after each cohort of 10 participants.

For sample size calculation, it has been suggested that 7-10 interviews are adequate to determine the understandability of an item. ${ }^{12}$ Argentinian Spanish SSPedi was considered satisfactory when no more than 2 of the last 10 participants found the SSPedi instructions and each symptom hard to understand, no more than 2 of the last 10 participants were incorrect in their understanding of the SSPedi instructions, each symptom, and response scale, and other comments including those related to cultural relevancy did not suggest the need for changes. 
Table 2 Evaluation outcomes of SSPedi translation*†

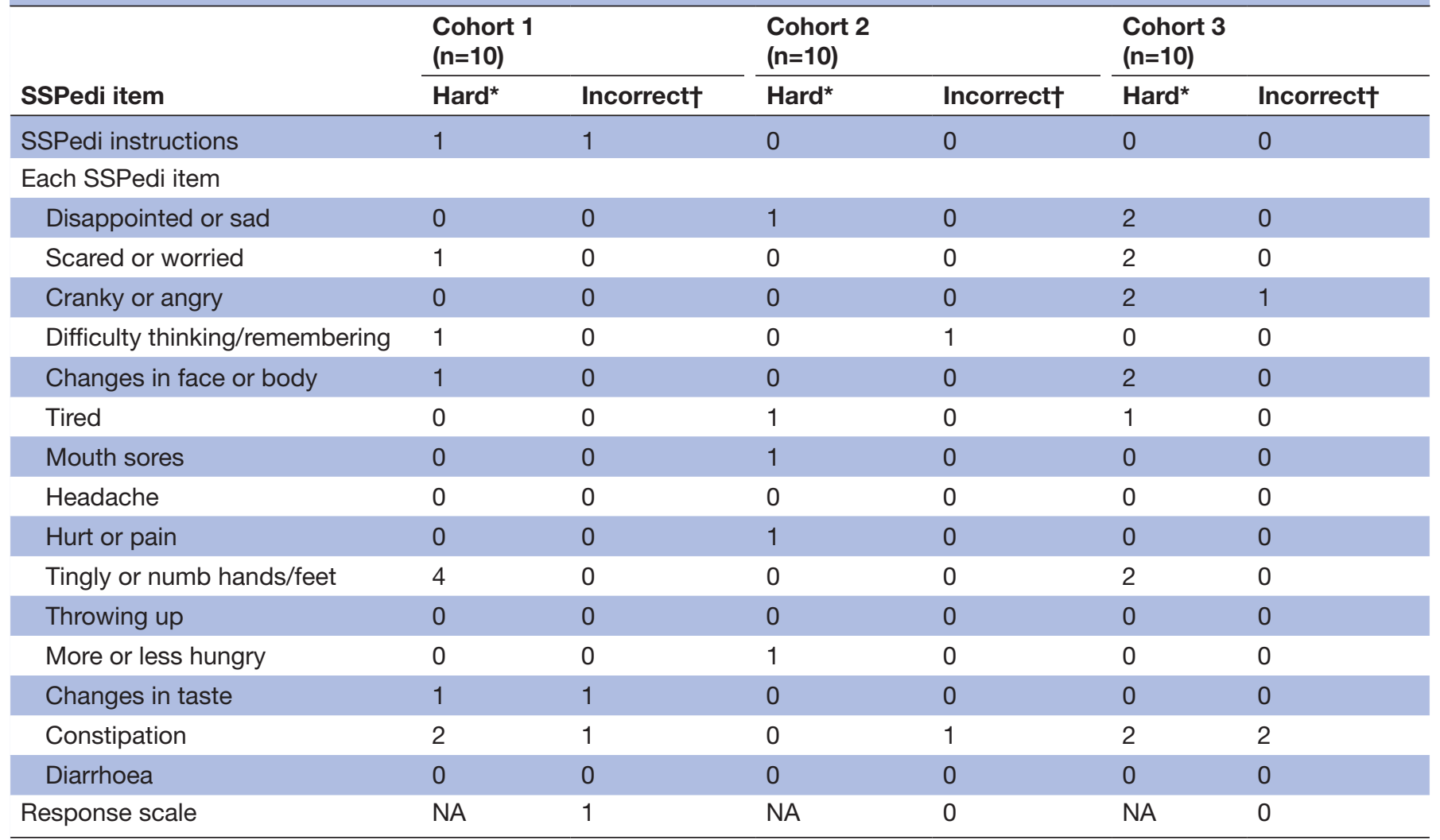

*How hard or easy was each section to understand as rated by participants. The number who rated the section as hard or very hard to understand is shown.

†Participant understanding of each section as rated by in-country interviewer and Toronto-based adjudicator. The number who were rated as mostly or completely incorrect is shown.

.NA, not assessed; SSPedi, Symptom Screening in Pediatrics Tool.

Thus, we planned to enrol up to $10-30$ children to allow for up to three iterations consisting of 10 children each.

\section{Patient and public involvement}

No patients were involved in study design or conduct apart from being participants in the research.

\section{RESULTS}

Forward translation, reconciliation and back translation were completed according to the protocol without any concerns. The translation panel's review of the back translation concluded that important discrepancies in meaning had not been introduced, and thus, the translated version was ready to proceed to evaluation by patients.

Between 30 May 2018 and 12 June 2019, we identified 33 potential participants. Figure 1 illustrates 30 participants were enrolled and describes the reasons for exclusion. Table 1 shows the demographics of the included participants. The number of children who were 8-10, 11-14 and 15-18 years of age were $5(17 \%), 17(57 \%)$ and $8(27 \%)$, respectively. The most common types of Spanish spoken were Central American $(17,57 \%)$ followed by South American $(10,33 \%)$ and Castilian $(3,10 \%)$. Of the 30 participants enrolled, 16 lived in Argentina and 14 lived in El Salvador.

Table 2 summarises the evaluation outcomes, namely, the number of participants who found each item hard or very hard to understand and the number of participants who were mostly or completely incorrect in their understanding of each item as adjudicated by the in-country interviewer and Toronto-based adjudicator. No changes to Argentinian Spanish SSPedi were required based on the outcomes or qualitative comments. During cohort 2, difficulty with understanding constipation became evident, and thus, another synonym (no puedes hacer caca) was added. Because of this modification, an additional cohort of 10 participants was enrolled even though the number of patients who found each SSPedi item hard to understand and the number who incorrectly understood each SSPedi item were favourable with the second cohort of 10 participants. After enrolment of 30 participants, Argentinian Spanish SSPedi was considered adequate. Across all three cohorts, the symptoms that were most challenging to understand were tingly or numb hands or feet and constipation. In cohort 3 , two participants were responsible for almost all the symptoms rated as hard to understand and all items that were misunderstood. 
(Argentine Spanish) SSPedi: detección de síntomas en pediatría

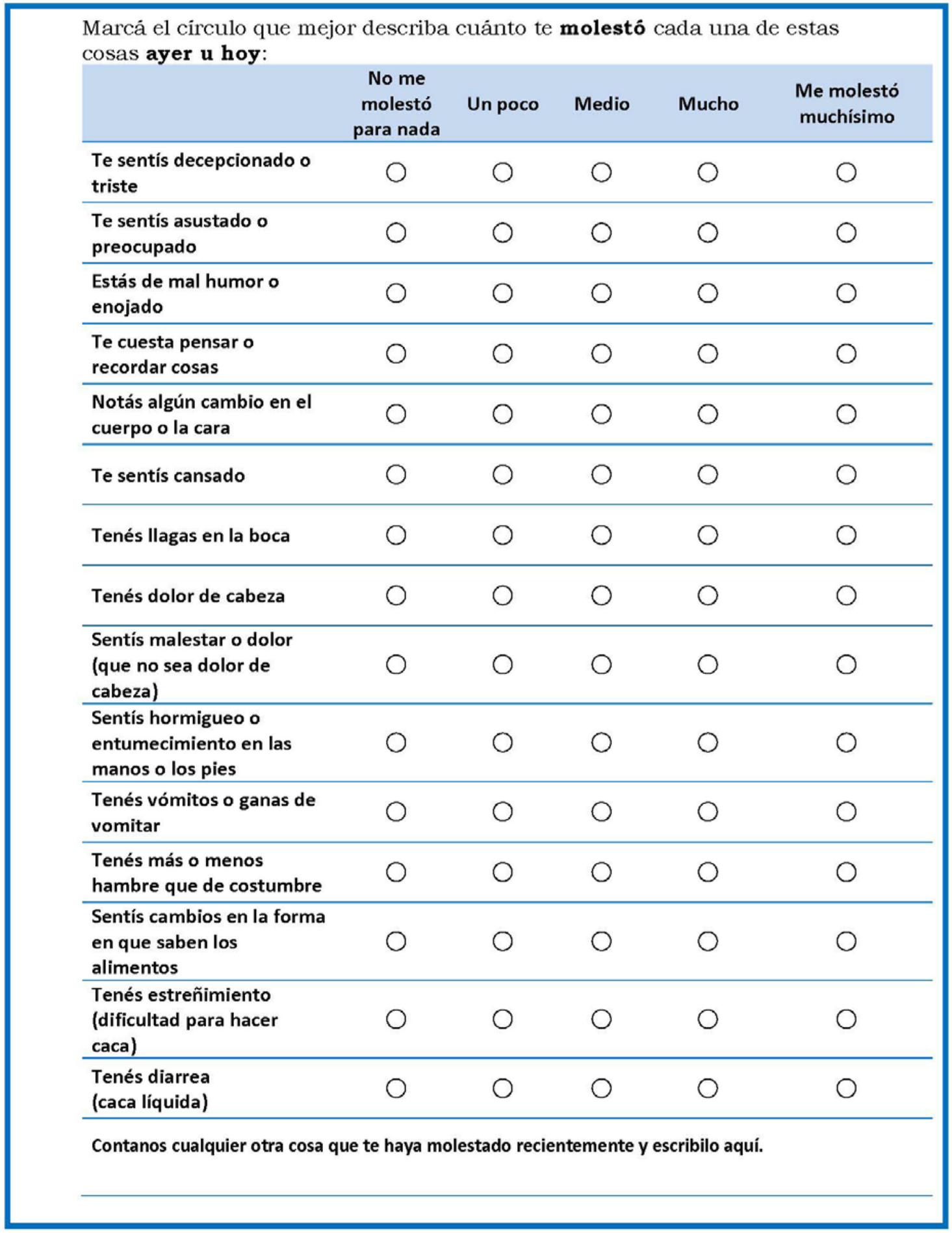

Fecha de la versión: 27 febrero 2018

Figure 2 Argentinian Spanish SSPedi (Symptom Screening in Pediatrics Tool).

No issues with cultural relevance were identified by any of the respondents. None of the children interviewed indicated that there were symptoms they felt were missing from the tool. Figure 2 shows the final version of Argentinian Spanish SSPedi.

\section{DISCUSSION}

Understanding that a distinct Argentinian version of Spanish SSPedi was required, we developed a translated tool that was appropriate based on difficulty in understanding, incorrect understanding and cultural 
relevance. While creation of separate versions of Spanish SSPedi is associated with additional effort to create, evaluate and maintain, this effort is worthwhile if it results in a paediatric symptom screening tool that optimises understanding.

We used a different threshold for acceptability in highincome versus middle-income or low-income countries. Both Argentina and El Salvador have struggled with providing education to children. Despite improvements to the education system in Argentina in recent years and impressive enrolment rates in both primary and secondary school, $22 \%$ of secondary students drop out and almost half will not graduate. ${ }^{1314}$ Statistics regarding enrolment, graduation and dropouts are even more stark in El Salvador, with only $62 \%$ of children enrolling in secondary school and $37 \%$ of these children dropping out before graduation. ${ }^{13}{ }^{15}$ Additionally, students in Latin America have consistently performed poorly (in the lower third of all participating countries) on international standardised tests. ${ }^{13}$

Given we know that some children in high-income countries have difficulty understanding symptoms, we were faced with a pragmatic choice when considering translating SSPedi for low-income and middle-income settings. If we set the same thresholds as used in highincome countries, then we might never be able to develop a satisfactory tool regardless of the changes made. This approach might increase disparities in lower income settings by withholding implementation of patientreported outcomes. In terms of incorrect understanding, the one item that was incorrectly understood by two children in the last cohort was constipation. We suggest that in these settings, the first administration of Argentinian Spanish SSPedi be done in the presence of a facilitator, who can anticipate and explain difficult to understand concepts. Creating a systematic process to facilitate completion of symptom screening tools for these settings should be a priority.

A strength of this study was the multiple approaches to evaluating understandability and the audio-recording of interviews, which allowed an external assessment of outcomes. However, this report is limited by conduct in only two centres and enrolment of a small number of subjects. Future studies should confirm appropriate psychometric properties of Argentinian Spanish SSPedi. Finally, the sample was slightly over-represented by males and predominated by patients with leukaemia or lymphoma and those 11-14 years of age. This may affect the generalisbility of our results.

In summary, we translated and finalised Argentinian Spanish SSPedi. Future research will focus on its use to describe bothersome symptoms by Argentinian Spanishspeaking children.

\section{Author affiliations}

${ }^{1}$ Stem Cell Transplantation Unit, Hospital de Niños Sor María Ludovica, La Plata, Argentina
${ }^{2}$ Department of Oncology, Hospital Nacional De Ninos Benjamin Bloom, San Salvador, El Salvador

${ }^{3}$ Child Health Evaluative Sciences, Hospital for Sick Children Research Institute,

Toronto, Ontario, Canada

${ }^{4}$ Division of Hematology-Oncology, The University of Texas Health Science Center at San Antonio, San Antonio, Texas, USA

${ }^{5}$ Department of Pharmacy, The Hospital for Sick Children, Toronto, Ontario, Canada ${ }^{6}$ Division of Haematology/Oncology, The Hospital for Sick Children, Toronto, Ontario, Canada

Acknowledgements We thank all the translators who worked with us on this project and whose expertise and insights greatly assisted the translation and evaluation process.

Contributors LD and LS developed the study concept and design. SG, CS, EP, GG and GD were involved in data collection. LS drafted the manuscript. All authors $\mathrm{SG}, \mathrm{CS}, \mathrm{EP}, \mathrm{GG}, \mathrm{GD}, \mathrm{AG}, \mathrm{AS}, \mathrm{AML}, \mathrm{LD}$ and $\mathrm{LS}$ participated in data interpretation, reviewed, revised and approved the manuscript.

Funding The authors have not declared a specific grant for this research from any funding agency in the public, commercial or not-for-profit sectors.

Competing interests None declared.

Patient consent for publication Not required.

Ethics approval This multiphase, descriptive study was approved by The Hospital for Sick Children's Research Ethics Board (\#1000057560) and the Research Ethics Boards of all participating sites.

Provenance and peer review Not commissioned; externally peer reviewed.

Data availability statement Data are available upon reasonable request. The datasets used or analysed during the current study are available from the corresponding author on reasonable request.

Supplemental material This content has been supplied by the author(s). It has not been vetted by BMJ Publishing Group Limited (BMJ) and may not have been peer-reviewed. Any opinions or recommendations discussed are solely those of the author(s) and are not endorsed by BMJ. BMJ disclaims all liability and responsibility arising from any reliance placed on the content. Where the content includes any translated material, BMJ does not warrant the accuracy and reliability of the translations (including but not limited to local regulations, clinical guidelines, terminology, drug names and drug dosages), and is not responsible for any error and/or omissions arising from translation and adaptation or otherwise.

Open access This is an open access article distributed in accordance with the Creative Commons Attribution Non Commercial (CC BY-NC 4.0) license, which permits others to distribute, remix, adapt, build upon this work non-commercially, and license their derivative works on different terms, provided the original work is properly cited, appropriate credit is given, any changes made indicated, and the use is non-commercial. See: http://creativecommons.org/licenses/by-nc/4.0/.

ORCID iD

Lillian Sung http://orcid.org/0000-0003-0951-3091

\section{REFERENCES}

1 Baggott C, Dodd M, Kennedy C, et al. Changes in children's reports of symptom occurrence and severity during a course of myelosuppressive chemotherapy. J Pediatr Oncol Nurs 2010;27:307-15.

2 Miller E, Jacob E, Hockenberry MJ. Nausea, pain, fatigue, and multiple symptoms in hospitalized children with cancer. Oncol Nurs Forum 2011;38:E382-93.

3 Pöder U, Ljungman G, von Essen L. Parents' perceptions of their children's cancer-related symptoms during treatment: a prospective, longitudinal study. J Pain Symptom Manage 2010;40:661-70.

4 Dupuis LL, Cook S, Robinson PD, et al. Optimizing symptom control in children and adolescents with cancer. Pediatr Res 2019;86:573-8.

5 Sung L. Priorities for quality care in pediatric oncology supportive care. J Oncol Pract 2015;11:187-9.

6 Dupuis LL, Ethier M-C, Tomlinson D, et al. A systematic review of symptom assessment scales in children with cancer. BMC Cancer 2012;12:430.

7 Tomlinson D, Dupuis LL, Gibson P, et al. Initial development of the symptom screening in pediatrics tool (SSPedi). Support Care Cancer 2014;22:71-5. 
8 Larouche V, Revon-Rivière G, Johnston D, et al. Translating the symptom screening in pediatrics tool (SSPedi) into French and among French-speaking children receiving cancer treatments, evaluating understandability and cultural relevance in a multiplephase descriptive study. BMJ Open 2020;10:e035265.

9 Plenert E, Grimes A, Sugalski A, et al. Translating the symptom screening in paediatrics tool (SSPedi) into North American Spanish and among Spanish-speaking children receiving cancer treatments: evaluating understandability and cultural relevance in a multiplephase descriptive study. BMJ Open 2020;10:e037406.

10 Wild D, Grove A, Martin M, et al. Principles of good practice for the translation and cultural adaptation process for patient-reported outcomes (pro) measures: report of the ISPOR Task force for translation and cultural adaptation. Value Health 2005;8:94-104.

11 O'Sullivan C, Dupuis LL, Gibson P, et al. Refinement of the symptom screening in pediatrics tool (SSPedi). Br J Cancer 2014;111:1262-8.

12 Willis G. Cognitive interviewing: a tool for improving questionnaire design. Sage Publications, 2009.

13 Bassi M, Busso M, Munoz J. Enrollment, graduation, and dropout rates in Latin America: is the glass half empty or half full? Economía 2015;16:113:5-56.

14 UNESCO Institute for Statistics. Argentina, 2020. Available: http://uis. unesco.org/en/country/ar

15 UNESCO Institute for Statistics. El Salvador, 2020. Available: http:// uis.unesco.org/en/country/sv 